\title{
Pengaruh Rating Film Terhadap Jumlah Audience Yang Menonton Film
}

\author{
Nissa Almira Mayangky ${ }^{1}$, Desiana Nur kholifah ${ }^{2}$, Imanuel balla ${ }^{3}$, Indra Jiwana Thira ${ }^{4}$ \\ ${ }_{1,2,3,4}$ STMIK Nusa Mandiri

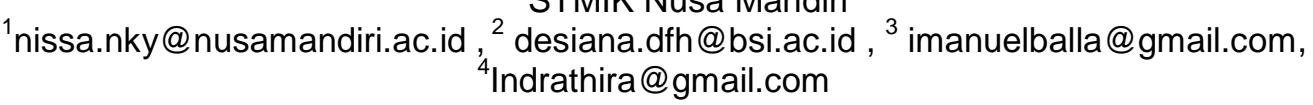

\begin{abstract}
Films become one of the forms of entertainment offered and sought after by viewers through the adaptation of novels, comics or television series, as well as various media. The development of the film from year to year is growing and starting to demand. The hope of the audience in searching for, using and evaluating a film has made the film world currently a major focus of filmmakers in channeling their hobbies, interests, talents, and efforts. This research was conducted to find out about whether the ratings assessed or graded from the film determine the number of viewers. This research uses descriptive quantitative method. The population in this study were all viewers of box office films in 2014-2015. This study uses 2 variables, rating and display with 696 data. Data processing used linear regression algorithm. Results of data processing which implements linear regression analysis on rapidminer shows the effect of film rating is only 0.011 . This small number value shows the effect that the film rating has on the number of viewers is not too significant or not needed.
\end{abstract}

Keywords: Watch Decision, Movie Rating, Number of Audiences, Regresi Linier.

Abstrak: Film menjadi salah satu bentuk hiburan yang ditawarkan dan diminati sejumlah audience dengan disajikan melalui adaptasi dari novel, komik, atau serial televisi, serta melalui berbagai macam media. Perkembangan perfilman dari tahun ke tahun semakin berkembang dan mulai diminati. Keinginan penonton dalam mencari, menggunakan dan menilai suatu film telah membuat dunia perfilman saat ini menjadi sorotan utama sineas dalam menyalurkan hobi, minat, bakat, dan usaha mereka. Penelitian ini dilakukan untuk mengetahui tentang apakah tingginya rating atau penilaian sebuah film berpengaruh pada banyaknya jumlah penonton. Penelitian ini menggunakan Metode kuantitatif deskriptif. Populasi dalam penelitian ini adalah semua penonton film box office tahun 2014-2015. Penelitian ini menggunakan 2 variabel yaitu rating dan views dengan jumlah data sebanyak 696 data. Pengolahan data yang digunakan algoritma regresi linier. Hasil pengolahan data implementasi algoritma regresi linier pada rapidminer menunjukan pengaruh rating film hanya sebesar 0,011 . Kecilnya angka rating ini menunjukan bahwa pengaruh yang diberikan rating film terhadap jumlah audience tidak terlalu signifikan atau tidak berpengaruh.

Kata kunci: Kepusan Penonton, Rating Film, Jumlah Penonton, Regresi Linier.

\section{A. PEndahuluan}

Film menjadi salah satu bentuk hiburan yang ditawarkan dan diminati sejumlah audience dengan disajikan melalui adaptasi dari novel, komik, atau serial televisi, serta melalui berbagai macam media. Menonton film telah menjadi kebiasaan dengan hadirnya film-film Hollywood yang menarik. Saat ini film-film Hollywood mempersiapkan film-film bersambung dan akan dilanjutkan pada film selanjutnya yang biasa disebut film sekuel. Para audiens atau pencinta film sebelum akhirnya mengambil keputusan dalam menonton mencari sebuah informasi tentang penilaian sebuah film melalui penilaian yang telah dibuat oleh kritikus film atau bahkan oleh audience yang telah menonton film tersebut. 
Kemajuan ilmu pengetahuan dan teknologi ditandai oleh kemajuan informasi dan komunikasi. Merambahnya teknologi informasi dalam kehidupan sehari-hari menimbulkan luapan informasi dalam bentuk digital maupun elektronik. (Pangestu, Jumhur, \& Hum, 2018) menyatakan bahwa informasi dalam bentuk digital dapat didistribusikan melalui media internet. Internet menawarkan alternative baru dalam memperoleh informasi baru sekaligus menyebarluaskan informasi itu sendiri. Internet merupakan jaringan computer berskala internasional yang dapat membuat masing-masing computer saling berkomunikasi dari berbagai tempat, negara, benua sehingga dapat berkomunikasi dengan protocol tertentu, saling mengirimkan dan mendapat informasi. Internet secaea tidak langsung merubah paradigma dalam mendapatkan informasi dan komunikasi, yang tidak lagi dibatasi oleh dimensi ruang dan waktu. Melalui internet semua orang bisa mendapatkan informasi dan berkomunikasi sesuai pribadi masing-masing.

Salah satu situs web yang menyediakan informasi mengenai film dari seluruh dunia adalah Internet Movie Database (IMDb), situs ini selain menampilkan rating film juga memberikan informasi orang-orang yang terlibat di dalamnya mulai dari aktor/aktris, sutradara, penulis sampai penata rias dan soundtrack. Koleksi informasi film yang ditampilkan cukup lengkap, kita bisa melihat informasi film-film lama maupun film terbaru yang akan rilis di bioskop. IMDb diluncurkan pada tanggal 17 oktober 1990 dan pada tahun 1998 diakuisisi oleh Amazon.com.

IMDb bisa menjadi sumber referensi untuk mencari film yang ingin ditonton. Didalamnya juga terdapat informasi yang berkaitan dengan film seperti, bio artis, nominasi yang pernah didapat, dan review dari para pengunjung. Ini mempengaruhi bagaimana cara kita mendapatkan informasi, dimana informasi dan hiburan dengan mudahnya kita akses lewat media digital. Selain itu, kita juga dapat berinteraksi satu sama lain antar sesama pengunjung dan memberikan tanggapan mengenai suatu film.

Pengguna IMDb di Indonesia mencapai 1.3\% dari seluruh dunia. Yaitu sekitar 1.3\% dari 57 juta visitors. Ini membuat Indonesia berada diperingkat 12 menurut statistik dari hypestat. Kebanyakan pengguna IMDb merupakan bukan pengguna unique. Dalam arti kata pengguna tidak menjadi member hanya mengunjungi situs dan mencari beberapa informasi tentang film. Perbandingannya sekitar 1 dari 5 mahasiswa di Bandung menjadikan IMDb acuan sebelum menonton film baik bioskop ataupun streaming.Dari satu forum menunjukkan tujuan para users menggunakan IMDb.com untuk melihat rating, dan melihat profil actor atau aktris kesukaan mereka sebelum menonton film. Ini memperlihatkan walaupun bukan sebagai pengguna unique, calon penonton tetap menggunakan IMDb sebagai sumber referensi untuk film yang akan ditonton maupun yang sudah ditonton. Untuk meneliti lebih jauh mengenai pengaruh rating film di kalangan audience, judul yang akan diambil Pengaruh Rating Film Terhadap Jumlah Audience Yang Menonton Film.

\section{B. TINJAUAN PUSTAKA}

\section{Keputusan Pembelian}

keputusan pembelian adalah suatu keputusan karena ketertarikan yang dirasakan oleh seseorang terhadap suatu produk, dan ingin membeli, mencoba, menggunakan, atau memiliki produk tersebut. Dalam keputusan membeli barang, konsumen sering kali ada lebih dari dua pihak yang terlibat dalam proses pertukaran atau pembeliannya (Marlius, 2017)

\section{Generasi Millenial}

generasi milenial adalah mereka yang lahir antara tahun 1980 sampai tahun 2000 . Sejalan dengan pernyataan tersebut BPS (2018) menyatakan pada tahun 2017 generasi milenial berada pada rentang usia 17-37 tahun. Berdasar dua pendapat tersebut maka dapat disimpulkan bahwa pada tahun 2019 generasi milenial berada pada rentang usia 19-39 tahun.(Lestari, 2019)

\section{Film}

Film adalah media komunikasi yang bersifat audio visual untuk menyampaikan suatu pesan kepada sekelompok orang yang berkumpul di suatu tempat tertentu. Pesan film pada komunikasi massa dapat berbentuk apa saja tergantung dari misi film tersebut. Akan tetapi, umumnya sebuah film dapat mencakup berbagai pesan, baik itu pesan pendidikan, hiburan dan informasi. Pesan dalam film adalah menggunakan mekanisme lambang-lambang yang ada 
pada pikiran manusia berupa isi pesan, suara, perkataan, percakapan dan sebagainya.(Dwi, 2018)

\section{Rating}

Rating adalah pendapat pelanggan pada skala tertentu. Sebuah skema peringkat popular untuk rating di toko online adalah dengan memberikan bintang. Semikin banyak memberikan bintang, maka menunjukkan peringkat penjual yang semakin baik. Rating dibuat oleh konsumen yang telah melakukan pembelian secara online dan dipublikasikan didalam website atau lapak dari penjual. Biasanya, rating adalah salah satu cara untuk memberikan umpan balik yang dilakukan oleh konsumen kepada penjual. Rating ini adalah tipe yang lain dari opini yang diberikan oleh banyak orang dan menjadi evaluasi rata-rata dari para pembeli-pemberi ratingterhadap perbedaan fitur dari produk ataupun service penjual dan menjadi representasi dari opini konsumen dengan skala yang spesifik (Auliya, Rifqi, Umam, \& Prastiwi, 2017)

\section{Regresi Linier}

Regresi linier adalah sebuah model yang menyatakan adanya hubungan linier antara dua variabel, dimana salah satu variabelnya dianggap sebagai pengaruh atau dapat memengaruhi variabel dependen [4]. Regresi linier dapat digunakan untuk menghitung jumlah bahan berdasarkan catatan keuangan dari bahan yg keluar permasing-masing menu. (Siagian, Widayanti, Agung, \& Agung, 2018)

Berikut merupakan rumus regresi linier.

$$
\begin{aligned}
& Y=a+b X \\
& b=\frac{\boldsymbol{n} \Sigma x y-\Sigma x \Sigma y}{n \Sigma x^{2}-(\Sigma x)^{2}} \\
& a=\frac{\Sigma y-b \Sigma x}{n}
\end{aligned}
$$

\section{METODE PENELITIAN}

\section{Populasi dan Sampel}

Populasi dalam penelitian ini adalah semua penonton film box office tahun 2014-2015. Penelitian ini menggunakan 2 variabel yaitu rating dan views..

\section{Data dan Sumber}

Data yang digunakan dalam penelitian ini sejumlah 696 data diambil dari situs https://archive.ics.uci.edu/ml/datasets.html

\section{Metode Pengumpulan Data}

Pengumpulkan data untuk penelitian ini adalah dengan cara online diambil dari website

\section{Metode Analisis Data}

Data dianalisis dengan menggunakan uji regresi linier sederhana, dan kemudian digunakan untuk menganalisis sejauh mana pengaruh rating terhadap jumlah penonton. 


\section{HASIL DAN PEMBAHASAN \\ Perhitungan Manual}

Hasil uji regresi linier sederhana untuk menguji variabel pengaruh $(x)$ terhadap variabel terpengaruh $(\mathrm{y})$ :

\section{Langkah 1 : Penentuan Tujuan.}

Tujuan: Untuk memprediksi jumlah views jika ratings 7

2. Langkah 2 : Identifikasi variabel penyebab dan akibat.

Variabel Faktor Penyebab (x) : Ratings

Variabel Akibat (y) : Views

3. Langkah 3 : Pengumpulan data.

Berikut ini adalah data penonton film box office tahun 2014-2015.

Tabel 1. Data Penonton film box office tahun 2014-2015.

\begin{tabular}{|l|l|l|l|}
\hline No & Movie & Ratings $(\mathrm{X})$ & Views $(\mathrm{Y})$ \\
\hline 1 & 13 Sins & 6.3 & 3280543 \\
\hline 2 & 22 Jump Street & 7.1 & 583289 \\
\hline 3 & 3 Days to Kill & 6.2 & 304861 \\
\hline 4 & 300: Rise of an Empire & 6.3 & 452917 \\
\hline 5 & A Haunted House 2 & 4.7 & 3145573 \\
\hline 6 & A Long Way Off & 4.6 & 91137 \\
\hline.. & $\ldots \ldots \ldots \ldots \ldots \ldots \ldots \ldots \ldots \ldots$ & $\ldots \ldots$ & $\ldots \ldots$. \\
\hline.. & $\ldots \ldots \ldots \ldots \ldots \ldots \ldots \ldots \ldots \ldots$ & $\ldots \ldots$ & $\ldots \ldots$ \\
\hline 230 & War Room & 5.4 & 66872 \\
\hline 231 & The Gallows & 4.4 & 659772 \\
\hline
\end{tabular}

4. Lalu buat tabel $(\mathrm{XY})$ atau perkalian antara Ratings $(\mathrm{X})$ dan jumlah Views $(\mathrm{Y})$.

Tabel 2. Perkalian Ratings dan Jumlah Views (XY).

\begin{tabular}{|l|l|l|l|l|}
\hline No. & Movie & Ratings $(\mathbf{X})$ & Views (Y) & $\mathbf{X Y}$ \\
\hline 1 & 13 Sins & 6.3 & 3280543 & 20667420.9 \\
\hline 2 & 22 Jump Street & 7.1 & 583289 & 4141351.9 \\
\hline 3 & 3 Days to Kill & 6.2 & 304861 & 1890138.2 \\
\hline 4 & 300: Rise of an Empire & 6.3 & 452917 & 2853377.1 \\
\hline 5 & A Haunted House 2 & 4.7 & 3145573 & 14784193.1 \\
\hline 6 & A Long Way Off & 4.6 & 91137 & 419230.2 \\
\hline.. & $\ldots \ldots \ldots \ldots \ldots \ldots \ldots \ldots \ldots \ldots$. & $\ldots \ldots$ & $\ldots \ldots$. &.. \\
\hline.. & $\ldots \ldots \ldots \ldots \ldots \ldots \ldots \ldots \ldots \ldots$. & $\ldots \ldots$. & $\ldots \ldots$. &.. \\
\hline 230 & War Room & 5.4 & 66872 & 361108.8 \\
\hline 231 & The Gallows & 4.4 & 659772 & 2902996.8 \\
\hline
\end{tabular}


5. Kemudian menentukan konstanta Ratings $(\mathrm{X})$ dan koefisien Views $(\mathrm{Y})$

Tabel 3. Konstanta Rating dan Koefisien Views.

\begin{tabular}{|c|c|c|c|c|c|c|}
\hline No & Movie & $\begin{array}{c}\text { Ratings } \\
\text { (X) }\end{array}$ & Views (Y) & $\mathbf{X Y}$ & $x^{\wedge} 2$ & $Y^{\wedge} 2$ \\
\hline 1 & 13 Sins & 6.3 & 3280543 & 20667420.9 & 39.69 & 10761962374849 \\
\hline 2 & 22 Jump Street & 7.1 & 583289 & 4141351.9 & 50.41 & 340226057521 \\
\hline 3 & 3 Days to Kill & 6.2 & 304861 & 1890138.2 & 38.44 & 92940229321 \\
\hline 4 & 300: Rise of an Empire & 6.3 & 452917 & 2853377.1 & 39.69 & 205133808889 \\
\hline 5 & A Haunted House 2 & 4.7 & 3145573 & 14784193.1 & 22.09 & 9894629498329 \\
\hline 6 & A Long Way Off & 4.6 & 91137 & 419230.2 & 21.16 & 8305952769 \\
\hline .. & 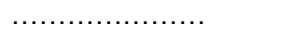 & $\cdots \cdots \cdots$ & ......... & …........ & ....... & 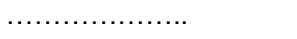 \\
\hline .. & $\ldots \ldots \ldots \ldots \ldots \ldots \ldots$ & $\ldots \ldots \cdots$ & $\ldots \ldots \ldots$ & $\ldots \ldots \ldots \ldots \ldots$ & $\cdots \cdots$ & 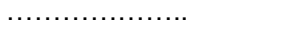 \\
\hline 230 & War Room & 5.4 & 66872 & 361108.8 & 29.16 & 4471864384 \\
\hline 231 & The Gallows & 4.4 & 659772 & 2902996.8 & 19.36 & 435299091984 \\
\hline \multicolumn{2}{|c|}{ Jumlah } & 1488 & 857668648.00 & 5536736076.70 & 9809.90 & 7864910288688500.00 \\
\hline
\end{tabular}

6. Kemudian menentukan konstanta Ratings $(X)$ dan koefisien Views $(Y)$

Tabel 4. Konstanta Ratings dan Koefisien Views.

\begin{tabular}{|c|c|c|c|c|c|c|}
\hline \\
\hline No & Movie & Ratings (X) & Views (Y) & $\mathbf{X Y}$ & $x^{\wedge} 2$ & $Y^{\wedge} 2$ \\
\hline 1 & 13 Sins & 6.3 & 3280543 & 20667420.9 & 39.69 & 10761962374849 \\
\hline 2 & 22 Jump Street & 7.1 & 583289 & 4141351.9 & 50.41 & 340226057521 \\
\hline 3 & 3 Days to Kill & 6.2 & 304861 & 1890138.2 & 38.44 & 92940229321 \\
\hline 4 & 300: Rise of an Empire & 6.3 & 452917 & 2853377.1 & 39.69 & 205133808889 \\
\hline 5 & A Haunted House 2 & 4.7 & 3145573 & 14784193.1 & 22.09 & 9894629498329 \\
\hline 6 & A Long Way Off & 4.6 & 91137 & 419230.2 & 21.16 & 8305952769 \\
\hline .. & & -....... & $\ldots \ldots \ldots$ & $\cdots \cdots \cdots$ & $\cdots \cdots$ & $\cdots \cdots \cdots$ \\
\hline .. & …… & $\ldots \ldots \ldots$ & $\ldots \ldots \ldots$ & $\ldots \ldots \ldots \ldots$ & $\cdots \cdots$ & 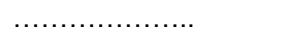 \\
\hline 230 & War Room & 5.4 & 66872 & 361108.8 & 29.16 & 4471864384 \\
\hline \multirow[t]{2}{*}{231} & The Gallows & 4.4 & 659772 & 2902996.8 & 19.36 & 435299091984 \\
\hline & Jumlah & 1488 & 857668648.00 & 5536736076.70 & 9809.90 & 7864910288688500.00 \\
\hline
\end{tabular}


7. Setelah itu Masukan kedalam Rumus persamaan Regresi.
a. Pembilang $=(\Sigma y)\left(\Sigma x^{2}\right)-(\Sigma x)(\Sigma x y)$
Penyebut $\quad \mathrm{n}\left(\Sigma \mathrm{x}^{2}\right)-(\Sigma \mathrm{x})^{2}$
$=\quad 174980387886$
51942.9
$=3368707$
b. Pembilang $=n(\Sigma x y)-(\Sigma x)(\Sigma y)$
Penyebut $\quad n\left(\Sigma x^{2}\right)-(\Sigma x)^{2}$
$=\quad 2775085493.70$
51942.9
$=53425.69$

8. Lalu persamaan Regresi yang diperoleh :

$\mathrm{Y}=\mathrm{a}+\mathrm{bX}$

$Y=3368707+53425.69 .1 X$

9. Lakukan Prediksi atau Peramalan terhadap Variabel Faktor Penyebab Ratings $(X)$ atau Variabel Akibat Views $(\mathrm{Y})$

$$
\begin{array}{ll}
Y= & 3368707+53425.69 .1(7) \\
Y= & 3742686.418
\end{array}
$$

Koefisien Determinasi $\mathrm{R}^{2}$

$$
\begin{aligned}
& r=\frac{n \Sigma x y-\Sigma x \Sigma y}{\sqrt{\left[n\left(\Sigma x^{2}\right)-(\Sigma x)^{2}\right]\left[n\left(\Sigma y^{2}\right)-(\Sigma y)^{2}\right]}} \\
& r=\quad 2775085494 \\
& {[26618.15] \quad[15342443193]} \\
& r=1599532139426250 \\
& R^{2}=2558503065057520000000000000000
\end{aligned}
$$

Standar Error Estimate Persamaan Regresi

$$
\begin{aligned}
& S_{\theta}=\sqrt{\frac{\Sigma y^{2}-a \Sigma y-b \Sigma x y}{n-2}} \\
& S_{e}=\mathbf{8 5 5 9 8 2 0 9 9 . 3}
\end{aligned}
$$

10. Implementasi data menggunakan aplikasi rapid miner : 
Berikut dataset yang diambil dari data pengunjung bioskop yang di convert ke aplikasi RapidMiner:

\begin{tabular}{|c|c|c|c|c|c|c|c|c|c|c|}
\hline Movie & Year & Ratings & Genre & Gross & Budget & Screens & Sequel & Sentiment & Views & 1 \\
\hline polyno... $\mathbf{V}$ & integer $\mathbf{v}$ & real & integer $\mathbf{v}$ & integer $\mathbf{v}$ & integer $\mathbf{v}$ & integer v & integer $\mathbf{v}$ & integer $\mathbf{v}$ & integer $\mathbf{V}$ & \\
\hline$\checkmark$ & attribute $\mathbf{v}$ & attribute $\mathbf{v}$ & attribute $\mathbf{v}$ & attribute $\mathbf{v}$ & attribute $\mathbf{v}$ & attribute $\mathrm{V}$ & attribute $\mathbf{v}$ & attribute $\mathbf{v}$ & label & \\
\hline 13 Sins & 2014 & 6.300 & 8 & 9130 & 4000000 & 45 & 1 & 0 & 3280543 & $\wedge$ \\
\hline 22. Jump... & 2014 & 7.100 & 1 & $1920000 \ldots$ & 50000000 & 3306 & 2 & 2 & 583289 & \\
\hline 3 Days t... & 2014 & 6.200 & 1 & 30700000 & 28000000 & 2872 & 1 & 0 & 304861 & \\
\hline 300: Ris... & 2014 & 6.300 & 1 & $1060000 \ldots$ & $1100000 \ldots$ & 3470 & 2 & 0 & 452917 & \\
\hline A Haunte... & 2014 & 4.700 & 8 & 17300000 & 3500000 & 2310 & 2 & 0 & 3145573 & v \\
\hline
\end{tabular}

Gambar 1. Dataset

11. Data yang sudah diimport kemudian dilakukan proses linier regression.. Berikut merupakan proses linier regresion:

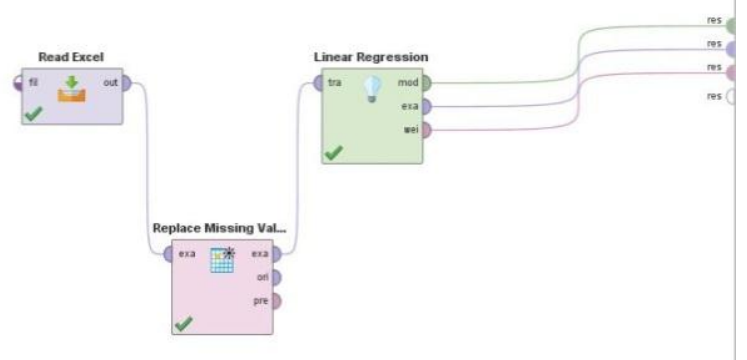

Gambar 2. Proses Linier Regresion

12. Berikut hasil regresi linier dari perhitungan RapidMiner:

Tabel 5. Hasil Perhitungan Regresi Linier.

\begin{tabular}{|c|c|c|c|c|c|c|c|}
\hline Atribut & Coefficient & Std.Error & Std.Coeffient & Tolerance & t-Start & p-Value & Code \\
\hline Ratings & 4129277.133 & 161777.424 & 0.090 & 0.992 & 2.552 & 0.011 & $\star \star$ \\
\hline
\end{tabular}

Tabel 5 menunjukan hasil perhitungan regresi linier menggunakan RapidMiner, berdasarkan data sejumlah 696 penonton film box office tahun 2014-2015. Penelitian ini menggunakan 2 variabel yaitu rating dan views memilliki coefficient 4129277.133, Std.Error 161777.424, Std.Coeffient 0.090, Tolerance 0.992, t-Start 2.552, p-Value 0.011.

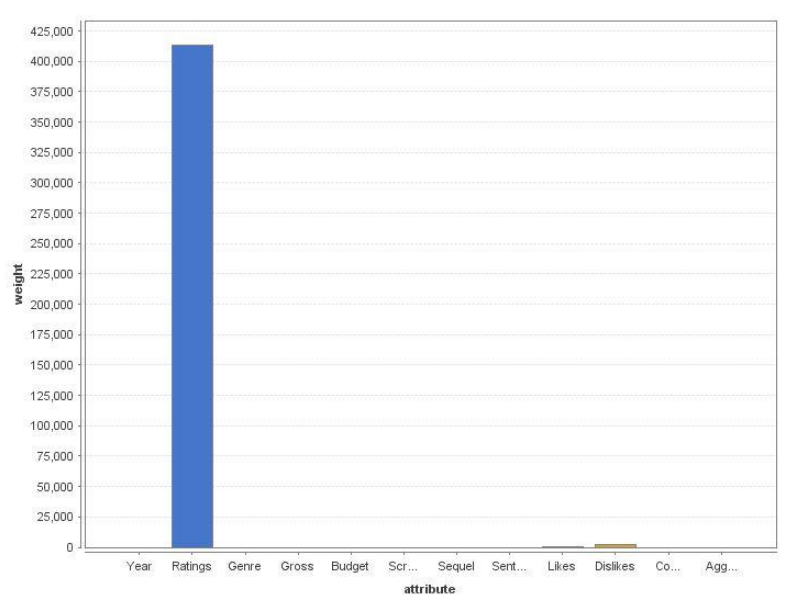

Gambar 3. Hasil Linier Rapidminer 


\section{KESIMPULAN}

Kesimpulan dari pengujian proses penelitian yang telah dilakukan dalam pengolahan data pada aplikasi rapidminer menggunakan metode regresi linier menunjukan pengaruh rating hanya sebesar 0,011 . Kecilnya angka rating ini menunjukan bahwa pengaruh yang diberikan rating film terhadap jumlah audience yang menonton film tidak terlalu signifikan atau tidak berpengaruh.

\section{REFERENSI}

Auliya, Z. F., Rifqi, M., Umam, K., \& Prastiwi, S. K. (2017). Online Costumer Reviews ( OTRs ) dan Rating: Kekuatan Baru pada Pemasaran Online di Indonesia Online Costumer Reviews ( OTRs ) dan Rating: New Era in Indonesia Online Marketing. 89-98.

Dwi, A. (2018). Faktor-Faktor yang Mempengaruhi Kesuksesan Film ( Studi Deskriptif Kualitatif Analisis Faktor-Faktor yang Mempengaruhi Kesuksesan Film Cek Toko Sebelah

Lestari, I. N. F. (2019). Hubungan Antara Subjective Well-Being Dengan Kepuasan Kerja Karyawan Generasi Milenial Di Pt. Telkom Regional Iv Jateng \& Diy.

Marlius, D. (2017). Keputusan Pembelian Berdasarkan Faktor Psikologis Dan Bauran Pemasaran Pt. Intercom Mobilindo Padang. Jurnal Pundi, 01(01), 57-66.

Pangestu, A. S., Jumhur, H. M., \& Hum, M. (2018). Pengaruh Rating Imdb Terhadap Keputusan Menonton Film Game Of Thrones Di Kota Bandung Tahun 2018 Impact Of Imdb Rating On The Decision To Watch Game Of Thrones Film In Bandung City In 2018. 5(3), 3253-3258.

Siagian, V., Widayanti, A., Agung, A., \& Agung, G. (2018). Aplikasi Estimasi Pengadaan Bahan Berdasarkan Catatan Akuntansi dengan Metode Regresi Linier. 116-119. 